\title{
ARTE REGIONAL DE MATO GROSSO DO SUL: A EDUCAÇÃO AMBIENTAL E AS AULAS DE ARTE
}

Alisquely Gonçalves de Barros ${ }^{1}$

Barbara Rodrigues Layoun²

Resumo: A Educação Ambiental pode estar articulada à arte e inserida no currículo como tema transversal a partir de atividades que proporcionem às crianças experiências com o reaproveitamento de materiais. $\mathrm{O}$ trabalho foi desenvolvido durante o segundo semestre do ano letivo de 2016 com o objetivo de levar os alunos à reflexão sobre a reutilização e redução de resíduos e a valorização da paisagem regional de Mato Grosso do Sul, a partir do estudo das obras do artista Isaac de Oliveira e da arte Kadiwéu. A metodologia seguiu a Proposta Triangular de Ana Mae Barbosa. Os resultados apontaram a contribuição das atividades para a aprendizagem dos alunos nos conceitos de Arte, o reconhecimento da arte regional e a motivação para ações no ambiente.

Palavras-chave: Reaproveitamento de Materiais; Cultura Regional; Proposta Triangular.

1 Universidade Federal de Mato Grosso do Sul - UFMS. E-mail: listufi@hotmail.com.

2 Universidade Federal de Mato Grosso do Sul - UFMS. E-mail: geografia.ms@gmail.com. 


\section{Introdução}

A Educação Ambiental pode ser entendida como um processo educativo do qual "o indivíduo e a coletividade constroem valores sociais, conhecimentos, habilidades, atitudes e competências voltadas para a conservação do meio ambiente, bem de uso comum do povo, essencial à sadia qualidade de vida e sua sustentabilidade". Entre os objetivos fundamentais da Educação Ambiental, pode ser citado o desenvolvimento de uma compreensão integrada do ambiente e suas relações com os aspectos sociais e culturais, e o incentivo à participação individual e coletiva na preservação do equilíbrio ambiental (BRASIL, 1999). Para que haja uma efetiva Educação Ambiental é necessária a introdução dos conceitos da sustentabilidade na formação escolar em todos os seguimentos, desde a educação infantil, e em todas as fases de um curso universitário.

$\mathrm{Na}$ escola, a Educação Ambiental, assim como toda atividade educativa, deve estar inserida no currículo escolar, contribuindo para a formação de alunos capazes de reconhecer sua própria realidade para transformá-la. A Política Nacional de Educação Ambiental ressalta que "a educação ambiental é um componente essencial e permanente da educação nacional, devendo estar presente, de forma articulada, em todos os níveis e modalidades do processo educativo, em caráter formal e não-formal' e prevê sua inserção, não como disciplina específica, mas como uma "prática educativa integrada, contínua e permanente em todos os níveis e modalidades do ensino formal' e inserido nos currículos de formação de professores (BRASIL, 1999).

A escola é um lugar favorável à Educação Ambiental por ser grande geradora de temas transversais como a produção de resíduos, por exemplo. Conforme os Parâmetros Curriculares Nacionais-PCN (BRASIL, 1997b, p. 37),

O convívio escolar será fator determinante para a aprendizagem de valores e atitudes. Considerando a escola como um dos ambientes mais imediatos do aluno, a compreensão das questões ambientais e as atitudes em relação a elas se darão a partir do próprio cotidiano da vida escolar do aluno.

Partindo do princípio que a Educação Ambiental é um processo contínuo, busca-se a reflexão e ação entre os alunos para que essas mudanças sejam espontâneas. Neste processo contínuo, o aluno ao reconhecer o ambiente no qual está inserido e sentir-se parte de todo o sistema pode trazer para si a responsabilidade na preservação do ambiente. Isto pode acontecer durante as aulas de Arte com a mediação de estudos e pesquisas sobre a arte regional, com foco na fauna e flora da região. Pois, ao sentir-se parte do ambiente, o aluno passa a entender que suas atitudes também influenciam o meio em que ele vive. 
O trabalho de sensibilização e motivação para ações ambientais na escola resgata a necessidade de conciliar a teoria com a prática no dia a dia, colaborando para a construção de uma sociedade consciente, em um ambiente saudável.

\section{Arte no Ensino Fundamental}

A arte possibilita ao aluno o desenvolvimento artístico no que se refere a sua sensibilidade, percepção e imaginação, tanto em sua produção/criação quanto durante a apreciação, aprendendo o respeito por produções dele e dos colegas, reconhecendo formas apresentadas pela natureza como também por diferentes culturas, épocas e estilos.

De acordo com os PCN de Arte (BRASIL, 1997a, p. 19),

O ser humano que não conhece arte tem uma experiência de aprendizagem limitada, escapa-lhe a dimensão do sonho, da força comunicativa dos objetos à sua volta, da sonoridade instigante da poesia, das criações musicais, das cores e formas, dos gestos e luzes que buscam o sentido da vida.

\section{O Ensino Fundamental tem-se como}

[...] um momento escolar especial na vida dos alunos, pois é nesse momento de seu desenvolvimento que eles tendem a se aproximar mais das questões do universo do adulto e tentam compreendê-las dentro de suas possibilidades. Ficam curiosas sobre temas como a dinâmica das relações sociais, as relações de trabalho, por que, como e por quem as coisas são produzidas (BRASIL, 1997a, p. 35).

Os alunos, nas aulas de Arte, passam a desenvolver pensamentos mais críticos, por meio de reflexões sobre o que se passa ao seu redor, contribuindo para torna-se uma pessoa mais questionadora com relação ao mundo.

Atualmente, a arte é produzida para se refletir, discutir, questionar e principalmente interagir. [...] A escola tem papel fundamental nessa aproximação, já que permite o encontro dos alunos com inúmeras situações expressivas e traz para a sala de aula imagens, propostas de conhecimento, apreciação e produção que podem auxiliar a formação de um cidadão que valorize a cultura, que seja crítico, participativo e inserido na sociedade (UGINO, 2013, p. 91). 
O ensino de Arte promove também o desenvolvimento dos sentidos e emoções. Assim, contribui para a transformação do sujeito mais reflexivo e emotivo, com um olhar diferente ao mundo, capaz de refletir, fruir e produzir.

Além de desenvolver a percepção e a imaginação, por meio da arte também é possível "apreender a realidade do meio ambiente, desenvolver a capacidade crítica, permitindo ao indivíduo analisar a realidade percebida $e$ desenvolver a criatividade de maneira a mudar a realidade que foi analisada" (BARBOSA, 2002, p. 18).

O aluno é conduzido a construir, experimentar, expressar e refletir sobre si e o mundo por intermédio da arte, considerando-a como área de conhecimento, com características únicas e fundamentais ao desenvolvimento do ser humano. A educação em arte promove ao indivíduo a capacidade de perceber, a partir da sensibilidade, o significado real das coisas. "[...] propicia $o$ desenvolvimento do pensamento artístico e da percepção estética, que caracterizam um modo próprio de ordenar e dar sentido à experiência humana: o aluno desenvolve sua sensibilidade, percepção e imaginação" (BRASIL, 1997a, p. 19).

A convivência com produções visuais e suas concepções estéticas nas diferentes culturas, tanto no âmbito regional, nacional e internacional, estão inseridos nos Parâmetros Curriculares Nacionais, nos blocos de conteúdos das artes visuais como objeto de apreciação significativa (BRASIL, 1997a). O estudo da paisagem regional ou local por meio da arte regional pressupõe uma compreensão mais significativa do ambiente em que se vive, e apreensão dos conteúdos.

\section{Cultura e arte de Mato Grosso do Sul e o currículo escolar}

A diversidade cultural faz parte do patrimônio de um povo que envolve os seguintes aspectos: folclore, música, artesanato, vestuário, culinária.

A formação cultural do sul-mato-grossense está ligada à diversidade das tradições trazidas por povos que no estado se instalaram, porém as que predominaram garantiram características muito peculiares à cultura local.

O autor Arias (2002, p. 103) afirma que a cultura é uma expressão especificamente humana e se caracteriza como construção da interação social, de uma realidade objetiva que permitiu a um grupo ou um indivíduo se constituir. Esta cultura se expressa nos significados e universos simbólicos que são socialmente compartilhados, e a identidade do grupo ou do indivíduo só pode ser construída a partir da cultura.

Sigrist (2000, p. 25-26) esclarece que, 
O homem, ser social, adquire desde cedo uma personalidade cultural, ou seja, um conjunto de traços que são comuns a todos os membros do grupo em que vive. Assim, quando ele é socializado aprende a ser humano e a adquirir o estilo de vida da comunidade. O processo cultural é, pois, um processo social e assim, um processo educativo.

Dentro do ambiente escolar, a disciplina de Arte pode contribuir nas relações estabelecidas entre os sujeitos. Documentos oficiais, tais como a Lei de Diretrizes e Bases da Educação Nacional - LDB, n 9.394, de 1996 e o Sistema Estadual de Ensino de Mato Grosso do Sul, Lei 2.787, de 2003, tratam do ensino de Arte e demonstram, entre outras especificidades, atenção com a cultura e principalmente com a cultura regional. Quando o professor parte do contexto do aluno contribui com a construção de sua identidade.

Esta atenção com o desenvolvimento da cultura, presente na Lei de Diretrizes e Bases da Educação Nacional - LDB, n 9.394 de 1996, diz que "o ensino da arte, especialmente em suas expressões regionais, constituirá componente curricular obrigatório da educação básica" (BRASIL, 1996).

Nesse sentido, o ensino de Arte irá propiciar a mediação, com um fazer reflexivo, consciente, sensível, gerando a leitura de mundo, abrindo diálogos com a diferença e com a própria identidade em construção, indo além de fronteiras geográficas e culturais.

Os PCN também abrangem a questão do ensino de Arte, para que o aluno desenvolva sua "sensibilidade, percepção e imaginação, tanto ao realizar formas artísticas quanto na ação de apreciar e conhecer as formas produzidas por ele e pelos colegas, pela natureza e nas diferentes culturas" (BRASIL, 1997a, p.19).

Para que haja uma formação de identidade, o indivíduo precisa reconhecer suas raízes culturais. É necessário que ele busque saber sobre sua cultura, sua arte, suas músicas, seu folclore e tradição, para que assim ele possa se integrar dentro da própria sociedade.

Os encantos da flora, paisagens e costumes de Mato Grosso do Sul são retratados em músicas, poemas, pinturas, esculturas e artesanatos. A diversidade cultural é um traço forte do estado que possui uma ampla identificação com a cultura indígena, mas também com remanescentes de comunidades quilombolas (CHAMORRO; COMBÈS, 2015).

A cultura de Mato Grosso do Sul possui também forte influência da cultura paraguaia e boliviana devido às fronteiras, entre outros povos. É um estado onde se encontra um mosaico cultural, ou seja, várias manifestações que fazem parte da identidade do povo sul-mato-grossense.

Segundo Sigrist (2000, p. 44), 
O uso dessas manifestações faz com que sejam legitimadas como cultura local, evidenciando, porém, as particularizações que elas adquirem. Isso pode ser observado na forma diferenciada com que essas manifestações se apresentam. Certamente, o caldo cultural sul-mato-grossense está sendo apurado pelas sucessivas gerações.

$\mathrm{Na}$ escola observa-se que nem sempre os conteúdos contemplam as manifestações da cultura local. É praticamente explícita a diferença entre culturas estudadas, confirmando que essa diversidade ainda é pouco discutida nas escolas, caracterizando a cultura local como uma cultura inferior ou desnecessária para o conhecimento.

Barbosa (2002, p. 19-20) explica que,

No que se diz respeito à cultura local, pode-se constatar que quase sempre apenas o nível erudito dessa cultura é admitido na escola (Tarsila, Portinari, etc.). As culturas de classes sociais economicamente desfavorecidas continuam a ser ignoradas pelas instituições educacionais, mesmo pelos que estão envolvidos na educação dessas classes.

A reflexão sobre a cultura local é necessária não só pela forma de um patrimônio, mas o que ele representa para um determinado grupo. $\mathrm{E}$ isso acontecerá no ensino de Arte, tendo suas manifestações como fator relevante na formação do cidadão.

A preservação e a valorização da paisagem e da cultura regional são componentes significativos do currículo que se relacionam à Educação Ambiental e devem ser abordadas como parte da constituição da identidade do sujeito, de sua formação cidadã, de sua cultura.

\section{Educação Ambiental e o currículo de Arte}

A Educação Ambiental adquire uma grande importância no mundo atual, composto por uma sociedade caracterizada pelo alto poder de risco ambiental, onde as explorações dos recursos naturais são cada vez mais devastadoras, levando o planeta a um futuro de destruição, fruto de uma cultura de consumismo desenfreado, do capitalismo, da industrialização, entre outros fatores que contribuem para uma crise ambiental.

Para Leff (2009, p. 18), a crise ambiental é uma crise do pensamento, e o saber ambiental "[...] constrói novas realidades e abre o curso da história para um futuro sustentável".

A Educação Ambiental deve estar presente diariamente na rotina da sala de aula, a ponto de ser transformada em sinônimo de cidadania. Deve estar presente nos currículos escolares e no desenvolvimento das práticas pedagógicas. Segundo Capra (2008, p. 32) o novo entendimento do processo 
de aprendizagem sugere novas estratégias de ensino e a necessidade de "um currículo integrado que valorize o conhecimento contextual, no qual as várias disciplinas sejam vistas como recursos à serviço de um objetivo central". Uma das formas sugeridas está baseada na aprendizagem por projetos, por fomentar experiências que engajem os alunos e pelos quais possam desenvolver habilidades e conhecimentos. $\mathrm{O}$ autor aborda ainda que as artes são um instrumento para ensinar, além de "reforçarem a dimensão emocional que tem sido cada vez mais reconhecida como um componente essencial do processo de aprendizagem" (CAPRA, 2008, p. 25).

Em relação ao referencial curricular, o tema ambiental pode estar inserido nas atividades artísticas e experiências práticas, em projetos ou atividades que conduzam os alunos como agentes ativos no processo (SATO, 2002 apud SILVA; REZENDE; FREITAS, 2017).

Desta forma, a escola quando for trabalhar o desenvolvimento do currículo escolar voltado para a questão ambiental, deve proporcionar a participação de todos no processo de sua execução, tendo os alunos como sujeitos do processo. Os conteúdos precisam estar interligados de forma interdisciplinar, além de terem sua importância dentro da Educação Ambiental.

Por ter uma abordagem interdisciplinar e ser tratada transversalmente no currículo escolar, a Educação Ambiental está articulada com a ArteEducação. Para Ruschmann (2007, p. 2),

A Educação Ambiental considerada como uma educação em valores, que trabalha com o conhecimento, a sensibilidade, o respeito e a formação de atitudes favoráveis ao meio ambiente tem como veículo de atuação a sua implicação desde os diversos campos de conhecimento.

Entende-se então que o ambiente e a arte estão interligados dentro da concepção de expressão de ideias e sentimentos. A arte fará essa ligação, do sujeito com a natureza.

Ruschmann (2007) explica também que há artistas que representam a natureza como beleza natural, realizam trabalhos com elementos próprios da natureza e outros denunciam as barbáries ecológicas, sugerindo reflexão sobre a interferência humana no ambiente natural.

Desta forma, os PCN (BRASIL, 1997a, p. 75-76) consideram que,

O ponto de partida do professor, focalizando genericamente a relação dos seres vivos com seu meio, tal como se expressa nas manifestações artísticas, abre perspectivas para a escolha de propostas para produção e apreciação de obras artísticas nas quais: 
- haja elementos para uma reflexão sobre ambientes naturais e construídos, urbanos e rurais, físicos e sociais;

- esses elementos permitam uma discussão sobre a harmonia e o equilíbrio necessários para a preservação da vida no planeta;

- seja possível reconhecer modos como as manifestações artísticas intervêm no ambiente natural.

Assim, pensou-se em um projeto dentro das aulas de Arte, voltado para questões ambientais com alunos do segundo ano do Ensino Fundamental, utilizando-se de materiais alternativos tendo como foco a arte regional de Mato Grosso do Sul, sua fauna e flora característica.

A ideia central foi trabalhar a criatividade reaproveitando materiais e problematizar com as crianças que os resíduos gerados também podem ser úteis, possibilitando a reflexão dos alunos sobre os danos que muitos materiais causam ao solo e aos rios, bem como realizar a prática artística por meio da reciclagem.

Nesta perspectiva, o projeto visou apresentar como o professor de Arte pode trabalhar a sustentabilidade a partir dos três " $R$ ": Reciclar, Reutilizar e Reduzir, dentro de sala de aula com seus alunos, de forma a contribuir para a valorização da arte regional e adquirir novos hábitos em relação à geração de resíduos, buscando a participação criativa durante as aulas, desenvolvendo novas habilidades, criatividade e reflexão, inserindo a Educação Ambiental no currículo de Arte.

A arte feita com materiais alternativos aproveita o "lixo" de uma sociedade de consumo. Para o arte-educador, esta sucata entra como material de pesquisa, de colagem, de construção, dando origem a objetos construtivos e expressivos.

Para este projeto os objetivos foram: Levar o aluno à reflexão da separação de resíduos que possam ser reaproveitados; Reutilizar os materiais domésticos e produzidos em sala para as aulas de arte; reduzir a geração de resíduos em sala de aula; valorizar a paisagem, fauna e flora regional; e reconhecer a arte regional com o estudo das obras do artista Isaac de Oliveira e da arte Kadiwéu.

\section{O artista Isaac de Oliveira e a arte Kadiwéu}

Pensando na fauna e flora da região de Mato Grosso do Sul, foi escolhido um artista que retratasse o ambiente ao qual os alunos estão inseridos, o pintor Isaac de Oliveira. O artista retrata em suas telas, além dos animais da região, a árvore ipê, que é árvore-símbolo do Cerrado brasileiro.

De acordo com Loureiro (s/d), Isaac de Oliveira chegou a Mato Grosso do Sul há mais de 30 anos, vindo da Bahia. Pintou o seu primeiro quadro aos 
nove anos e encontrou um verdadeiro talento. Desde então, pinta muitas telas entre pássaros, peixes, ipês e flores, todos com sua principal característica: muita luz e cores vibrantes que chamam a atenção dos que apreciam. $O$ artista possui um estilo próprio. Fazendo uso de materiais de boa qualidade, Isaac mistura cores vivas e tropicais, tornando seu trabalho diferenciado, único e muito expressivo. Assim, ele consegue retratar a exuberância da natureza com suas cores.

Desde que passou a morar em Mato Grosso do Sul ele expressa sua arte e inspirações que encontrou na beleza da fauna e flora pantaneira. A partir daí, onças e peixes do pantanal, pássaros, flores do Cerrado e seus ipês ultrapassaram fronteiras e ganharam o mundo.

Tratando-se de Educação Ambiental, observou-se também a necessidade de se fazer o reconhecimento da arte regional de Mato Grosso do Sul a partir da arte indígena. Cultura forte no estado, a arte indígena surge no projeto a partir de suas tintas naturais. E dentro da arte regional tem-se a arte dos índios Kadiwéu. A arte dos índios Kadiwéu foi escolhida por apresentar em sua iconografia muitas cores e formas.

Os índios Kadiwéu foram elementos de estudo de Darcy Ribeiro, um dos maiores antropólogos brasileiros. O artista Jean-Baptiste Debret (17681848) também os representou em seus trabalhos.

A arte Kadiwéu é representada nas cerâmicas e também nos finos desenhos corporais realizados pelos Kadiwéu. Excelentes desenhistas estampam nos rostos com desenhos minuciosos e simétricos, traçados com a tinta extraída da natureza. No passado, a pintura corporal marcava a diferença entre nobres, guerreiros e cativos (PECHINCHA, 1999).

Segundo Ribeiro (1980), na arte Kadiwéu, há sempre a busca pelo equilíbrio, ainda que diagonal ou incompleta. Eles utilizam praticamente todas as formas geométricas conhecidas por nós, linhas retas e curvas, espirais e degraus. "As cores usadas tradicionalmente são o preto azulado do jenipapo, o vermelho do urucum e o branco extraído da palmeira bocaiúva" (RIBEIRO, 1980, p. 278-279).

As cerâmicas são produzidas pelas mulheres Kadiwéu: vasos e pratos para decoração de diversos tamanhos e formatos, reproduzindo animais da região. A matéria-prima de seu trabalho é encontrada em barreiros que contêm o barro apropriado e da consistência e tonalidade ideais para a produção. Para a pintura, as tintas são feitas a partir de pigmentos conseguidos de areias dos mais variados tons, usando também a resina de pau-santo para envernizar (PECHINCHA, 1999). 


\section{Arte regional e Educação Ambiental em sala de aula}

O projeto foi desenvolvido em uma escola pública municipal de Campo Grande (MS), com uma turma do segundo ano do Ensino Fundamental, com 27 alunos na faixa etária de 7 a 9 anos. Todo o trabalho foi realizado no decorrer de 10 aulas, no período de outubro a novembro de 2016. A sequência didática foi organizada em fases: apreciação, reflexão e produção, de acordo com a Proposta Triangular formulada pela arte-educadora Ana Mae Barbosa.

A abordagem triangular preconiza um ensino de arte fundamentado em três eixos de ação: o fazer artístico; a leitura (apreciação da obra de arte) e contextualização da imagem (história da arte). [...] ficou conhecida na década de 80 , e tornou-se a nova referência pedagógica para a educação em Arte, baseada na história, crítica e produção estética (ler-fazercontextualizar) (OLIVEIRA, 2009. p. 10-17).

A abordagem triangular "[...] propõe que o currículo escolar articule as dimensões da leitura das produções do campo da arte, sua produção e contextualização" (COUTINHO, 173). Por ser uma proposta que busca trabalhar em conjunto os três eixos da arte: apreciação, produção e reflexão, se relacionam às diretrizes nacionais, pois no currículo de Arte "trata-se de estudos sobre a educação estética, a estética do cotidiano, complementando a formação artística dos alunos" (BRASIL, 1997a, p. 25).

A Proposta Triangular foi aplicada tanto com a arte de Isaac de Oliveira quanto com a arte Kadiwéu. As aulas foram divididas em duas etapas: a primeira foi com o trabalho de Isaac de Oliveira e a segunda, com a arte Kadiwéu.

Na primeira etapa, os alunos puderam conhecer a vida e obra do artista Isaac de Oliveira por intermédio de slides, reconhecendo a fauna e flora regional de Mato Grosso do Sul tão presentes nas obras do artista. Nesse primeiro contato, ocorreu uma grande participação dos alunos, com discussões sobre o que estava sendo representado nas obras e os alunos demonstraram interesse pelas cores vibrantes nas pinturas. O foco maior para essa apreciação foram os ipês e suas cores. No primeiro momento, os alunos não reconheceram a árvore como sendo característica da região do Cerrado. Após terem descoberto, por meio de fotos dos ipês da região, que é uma árvore presente na própria comunidade, ficaram surpresos, pois perceberam que conheciam a árvore, mas não haviam percebido suas cores e sua beleza.

Os alunos foram incentivados a observarem, durante o caminho que fazem na ida e volta da escola, a existência de árvores ipês e quais cores das flores mais encontram. E a resposta foi rápida e positiva. Todos trouxeram informações sobre os ipês que encontraram e alguns alunos até descobriram que tinham a árvore na própria casa.

revista brasileira educação ambiental 
Segundo Sousa (2005, p. 17) "[...] a percepção é estabelecida na relação entre os estímulos percebidos pelos sentidos e as respostas próprias do sujeito sensível que, como vimos, responde com sensações, sentimentos e ideias, quando é estimulado".

Os alunos fizeram registros coletivos sobre a árvore pesquisada, e representações gráficas. Houve roda de conversa com os alunos sobre a importância do ambiente, e a mediação promoveu a participação dos alunos na discussão sobre o que está acontecendo com a natureza. Muitos deles relataram algum tipo de falta de respeito com o meio ambiente, e principalmente com o fato de jogar o lixo no chão, o que facilitou a mediação sobre o reaproveitamento de materiais que, normalmente, vão para o lixo. Alguns alunos relataram possuir um familiar que faz esse tipo de trabalho, e isso contribuiu o entendimento dos três "R": Reduzir, Reutilizar e Reciclar.

Como produção dessa primeira etapa, realizaram pintura sobre papel A4 a partir das obras dos ipês de Isaac de Oliveira e dos próprios ipês que pesquisaram pela comunidade. Fizeram moldura nos trabalhos com recortes de revistas.

Uma das aulas foi organizada para uma exposição, na própria sala de aula, com as atividades finalizadas, com o objetivo de promover uma reflexão sobre todo o processo de produção e a importância do ambiente e sua preservação. Os alunos fizeram a apreciação de seus trabalhos e a de seus colegas, gerando elogios, críticas construtivas e motivação em relação às produções.

$\mathrm{Na}$ segunda etapa do projeto foi apresentada a arte Kadiwéu aos alunos por intermédio de slides, focando suas cores e formas na cerâmica, o modo como os indígenas, de modo geral, retiram da natureza tudo o que precisam sem prejudicar o ambiente, incluindo o barro para a produção das cerâmicas e as tintas que usam nas pinturas corporais e cerâmicas.

A curiosidade por parte dos alunos foi relevante, porém, poucos conheciam a arte Kadiwéu. Por isso, a partir deste resultado decidiu-se priorizar a ênfase às formas que os Kadiwéu utilizam em seus desenhos, seja na pintura corporal ou cerâmica, abordando conceitos já estudados nas linhas encontradas nas obras de Isaac de Oliveira, fazendo sempre a ligação entre o artista e a arte regional.

Os alunos foram motivados a fazerem estudos sobre as formas e linhas da arte Kadiwéu, lembrando-se das cores alegres da natureza.

A questão ambiental esteve presente no currículo em toda a sequência didática. Os alunos foram motivados a produzirem um desenho no caderno de Arte usando apenas as cores da arte Kadiwéu e a produção da árvore ipê. Durante a abordagem dos pigmentos, a ênfase foi para a matéria-prima encontrada em barreiros especiais que contêm a consistência e tonalidade ideais para a cerâmica e as cores da arte Kadiwéu, que conforme Duran (2015) apresentam o preto, marrom e vermelho, por exemplo, extraídos de elementos da natureza.

Revbea, São Paulo, V. 13, № 3: 26-41, 2018. 
Os alunos foram convidados a produzirem suas tintas naturais utilizando ingredientes como o pó de café, a erva mate e o urucum (pigmento). Os alunos ficaram entusiasmados com a produção, principalmente com o cheiro do café que abrangeu toda a sala de aula, e muito envolvidos com a atividade, por estimular todos os sentidos. Após a produção de tintas, realizaram a pintura sobre $\mathrm{A} 4$ usando suas tintas naturais.

Esta atividade possibilitou uma experiência estética, de imaginação e criação, que amplia os limites do intelecto. Os sentimentos foram estimulados devido aos aromas e texturas, e nesse sentido a arte colabora para educar os sentimentos e as emoções, "[...] a arte se constitui num estímulo permanente para que nossa imaginação flutue e crie mundos possíveis, novas possibilidades de ser e sentir-se. Pela arte a imaginação é convidada a atuar [...]" (DUARTE JÚNIOR, 2008, p. 67).

A sequência didática permitiu uma discussão da professora com os alunos sobre a arte de Isaac de Oliveira, a importância da preservação do ambiente e a arte regional. Essa discussão proporcionou uma melhor reflexão sobre a questão ambiental e quanto ao desperdício de papéis em sala de aula. Esta reflexão contribuiu para a percepção dos alunos quanto ao desperdício e abordagem da derrubada de árvores para a produção do papel utilizado em sala.

As atitudes dos alunos relacionadas à diminuição da geração dos resíduos na sala de aula demonstram que o contato com a arte Kadiwéu e o reaproveitamento de materiais gerou uma maior percepção dos alunos quanto aos elementos da natureza utilizados para a produção dos materiais e também em relação à cultura regional.

"A percepção e o engajamento do cidadão em relação à importância dos elementos naturais e aos problemas ambientais locais são um passo importante para contemplar os objetivos da Educação Ambiental" (MELAZO, 2005 , p. 48). Além disso, a arte possibilita à criança o conhecimento de si mesma "nas suas capacidades e limitações e o seu contexto, com suas mensagens e símbolos. Ao compreender o que ocorre à sua volta, ela poderá interagir com o entorno, tomar suas próprias decisões e até transformar esse entorno" (PROSSER, 2012, p. 13).

Com foco na reutilização de materiais, os alunos fizeram uma produção unindo a arte de Isaac de Oliveira e a arte Kadiwéu utilizando rolinhos de papel higiênico que eles providenciaram. A proposta foi construir um ipê usando os rolinhos e as tintas naturais sobre A4. Cada aluno desenvolveu seu trabalho levando em consideração sua criatividade e estética. A preocupação com a sobra de rolinhos estimulou-os a pensarem em novas possibilidades de produções artísticas. E este resultado revelou como o trabalho da Arte e Educação Ambiental deve ser contínuo, pois em aulas posteriores os alunos demonstraram interesse pela questão ambiental.

As atividades desenvolvidas estiveram em consonância com o conceito de arte-educação, sendo esta uma educação aliada à arte permitindo uma 
maior sensibilidade para o mundo (DUARTE JÚNIOR, 2008). O destaque da arte-educação de mediar a arte e o público é apontado pelo papel importante que a arte tem na mediação entre os seres humanos e o mundo, na compreensão da arte-educação como mediação cultural e social (BARBOSA, 2009).

"A arte, como uma linguagem aguçadora dos sentidos, transmite significados que não podem ser transmitidos por nenhum outro tipo de linguagem, como a discursiva e a científica". A apreensão da realidade do meio ambiente e o desenvolvimento da capacidade crítica de análise desta realidade podem ser desenvolvidos por meio da arte permitindo que a criatividade se desenvolva de modo a mudar a realidade analisada (BARBOSA, 2009, p. 21).

Durante as aulas de Arte, com o estudo e a pesquisa sobre a arte regional, os alunos reconheceram o ambiente a que estavam inseridos $e$ sentindo-se parte de todo esse sistema trouxeram para si a responsabilidade da preservação do ambiente, revelando que a busca da reflexão e ação como princípio da Educação Ambiental é um processo que deve ser contínuo, inserido nos currículos escolares e no desenvolvimento das práticas pedagógicas.

\section{Conclusões}

Os resultados revelaram a necessidade de se inserir a Educação Ambiental dentro das escolas, principalmente com as crianças pequenas, pois nesta fase da infância, seu processo de formação contribuirá para que se tornem adultos com ações positivas em favor do ambiente ao qual estão inseridos.

E tudo isso foi possível perceber nas aulas de Arte, trabalhando dentro do currículo a Educação Ambiental. Os alunos ficaram mais participativos, em todas as etapas, discussões, e ainda fizeram produções que mostraram a formação dos novos conceitos que estavam sendo formados. As aulas trouxeram resultados positivos para a participação e interesse dos alunos, pois a cada aula se empolgavam com o tema, com atividades, com pesquisas de campo.

Não ocorreram dificuldades durante a mediação na abordagem das questões ambientais, uma vez que estes temas estão inseridos nos conceitos abordados no currículo, em especial na valorização da arte regional de Mato Grosso do Sul, das paisagens naturais, da cultura regional e dos materiais utilizados para a produção artística. E a reutilização de materiais favorece as aulas de Arte, também o que tange a ampliação da criatividade, pois frequentemente faltam materiais apropriados para a releitura das obras. Os alunos se mostraram muito motivados a aprender mais sobre a arte regional, surpreendendo o resultado de que esta é praticamente desconhecida por eles. 
Ao trabalhar a proposta triangular de Ana Mae Barbosa, seguindo os três eixos: produção, fruição e reflexão, os alunos participaram dos momentos com bastante motivação.

O projeto poderia ter sido mais abrangente se houvesse um envolvimento de toda a escola, ou de outras disciplinas, como por exemplo, História, Geografia, Ciências, trabalhando também a Educação Ambiental, pois, observou-se que a Educação Ambiental ainda é pouco discutida na escola. Talvez por ser considerada como um conteúdo a mais, diante de tantos que os professores têm que dar conta. Um melhor esclarecimento sobre como trabalhar a Educação Ambiental de forma interdisciplinar, na formação dos professores, poderia contribuir para tornar mais fácil esse trabalho com os alunos e assim atingir um resultado melhor para a qualidade de vida.

A Educação Ambiental pode estar inserida naturalmente no currículo de Arte, principalmente na contextualização dos materiais utilizados e da cultura regional. Espera-se que os resultados incentivem outros professores a transformarem suas práticas pedagógicas.

\section{Referências}

ARIAS, P.G. La cultura. Estrategias conceptuales para entender la identidad, la diversidad, la alteridad y la diferencia. Quito-Ecuador: Ediciones Abya-Yala, 2002. $134 \mathrm{p}$.

BARBOSA, A.M. (Org.). Inquietações e mudanças no ensino da arte. São Paulo: Cortez, 2002. 184p.

BARBOSA, A.M. Mediação cultural é social. In: BARBOSA, A.M.; COUTINHO, R.G. (Org.). Arte/educação como mediação cultural e social. São Paulo: UNESP, 2009. p. 13-22.

BRASIL. Lei no 9.394, de 20 de dezembro de 1996. Estabelece as diretrizes e bases da educação nacional. Brasília, DF, 23 dez. 1996. Disponível em: $<$ https://www.planalto.gov.br/ccivil 03/Leis/L9394.htm>. Acesso em 29 jun. 2018.

BRASIL. Parâmetros Curriculares Nacionais: Arte. Brasília: MEC/SEF, 1997a. v. 6. Disponível em: <http://portal.mec.gov.br/seb/arquivos/pdf/livro06.pdf>. Acesso em: 17 nov. 2017.

BRASIL. Parâmetros Curriculares Nacionais: Meio ambiente e saúde. Brasília: SEF/MEC, $1997 b . \quad 128 \quad$ p. $\quad$ v. $\quad 9 . \quad$ Disponível em: $<$ http://portal.mec.gov.br/seb/arquivos/pdf/livro091.pdf>. Acesso em: 17 nov. 2016.

BRASIL. Lei no 9.795, de 27 de abril de 1999. Dispõe sobre a educação ambiental, institui a Política Nacional de Educação Ambiental e dá outras providências. Brasília, DF, 28 abr. 1999. Disponível em: $<$ http://www.planalto.gov.br/ccivil 03/Leis/L9795.htm>. Acesso em: 14 abr. 2018. 
BRASIL. Lei no 2.787, de 24 de dezembro de 2003. Dispõe sobre o Sistema Estadual de Ensino de Mato Grosso do Sul e dá outras providências. Campo Grande, MS, 29 dez. 2003. Disponível em: $<$ http://aacpdappls.net.ms.gov.br/appls/legislacao/secoge/govato.nsf/>. Acesso em: Acesso em 29 jun. 2018.

CAPRA, F. Alfabetização ecológica: o desafio para a educação do século 21. In: TRIGUEIRO, A. (Coord.). Meio ambiente no século 21: 21 especialistas falam da questão ambiental nas suas áreas de conhecimento. 5. ed. CampinasSP: Armazém do Ipê, 2008. p. 19-33.

CHAMORRO, G.; COMBÈS, I. (Org.). Povos indígenas em Mato Grosso do Sul: história, cultura e transformações sociais. Dourados, MS: UFGD, 2015.

COUTINHO, R.G. Estratégias de mediação e a abordagem triangular. In: BARBOSA, A.M.; COUTINHO, R.G. (Org.). Arte/educação como mediação cultural e social. São Paulo: UNESP, 2009. p. 172-185.

DUARTE JÚNIOR, J-F. Por que arte-educação? 19. ed. Campinas-SP: Papirus editora, 2008. (Coleção Agere).

DURAN, M.R.C. Leituras antropológicas sobre a arte kadiwéu. Cadernos de campo, São Paulo, n. 24, p. 43-70, 2015. Disponível em: $<$ https://edisciplinas.usp.br/pluginfile.php/3268089/mod resource/content/1/Cad uveo.pdf >. Acesso em: 10 mai. 2018.

LEFF, E. Complexidade, racionalidade ambiental e diálogo de saberes. Educação e realidade, Rio Grande do Sul, v. 34, n. 3, p.17-24, set./dez. 2009. Disponível em: <http://seer.ufrgs.br/index.php/educacaoerealidade/article/view/ 9515/6720>. Acesso em: 10 mai. 2018.

LOUREIRO, A.K. Isaac de Oliveira. Campo Grande-MS. Disponível em: $<$ http://isaacdeoliveira.com.br/?page id=26>. Acesso em: 21 ago. 2016.

MELAZO, G.C. Percepção ambiental e educação ambiental: uma reflexão sobre as relações interpessoais e ambientais no espaço urbano. Olhares e trilhas, Uberlândia, Ano VI, n. 6, p. 45-51, 2005. Disponível em: <http:// www.seer.ufu.br/index.php/olharesetrilhas/article/view/3477/2560>. Acesso em: 29 jun. 2018.

OLIVEIRA, A.P.F. Abordagem triangular na prática do arte-educador: aproximações, dilemas e dificuldades no cotidiano da sala de aula. 2009. $84 \mathrm{f}$. Trabalho de conclusão de curso. Universidade Federal do Pará, Belém, 2009.

PECHINCHA, M.T.S. Kadiwéu: arte. 1999. Disponível em: $<$ https://pib.socioambiental.org/pt/povo/kadiweu/266>. Acesso em: 27 out. 2016.

PROSSER, E.S. Ensino de artes. Curitiba- PR: IESDE Brasil, 2012.

RIBEIRO, D. Kadiwéu, ensaios etnológicos sobre o saber, o azar e a beleza. Petrópolis, Vozes, 1980. 
RUSCHMANN, C.B.F. Formação artística e consciência ambiental. Com Scientia, Curitiba, PR, v. 3, n. 4 3, jan./jun. 2007. Disponível em: $<$ http://www.educadores.diaadia.pr.gov.br/arquivos/File/2010/artigos teses/201 1/Arte/Artigos/formacao ruschmann.pdf>. Acesso em: 08 nov. 2017.

SIGRIST, M. Chão batido: a cultura popular de Mato Grosso do Sul - folclore, tradição. Campo Grande, MS: UFMS, 2000.

SILVA, R.A.F.; REZENDE, A.R.; FREITAS, C.M.C. Higiene ambiental: dos diálogos de educação ambiental à qualidade de vida. Cap. 10. In: ASSIS, W.F.M.P. (Org.). Ciências da natureza e formação de professores: entre desafios e perspectivas apresentados no CECIFOP 2017. Jundiaí, SP: Paco, 2017.

SOUSA, R.P.L. Roteiro didático da arte na produção do conhecimento. Campo Grande, MS: UFMS, 2005.

UGINO, A.P.M. A educação contemporânea de Arte: repensando o cotidiano da sala de aula. In: COUTINHO, R. G. (Coord.). Desafios para a docência em arte: teoria e prática. São Paulo: Cultura Acadêmica, 2013. p. 88-97. Disponível em: <https://acervodigital.unesp.br/bitstream/unesp/155332/1/unesp-neadredefor2ed-e-book-tcc arte.pdf>. Acesso em: 09 mai. 2018. 